\title{
Current status of cytopathology practices in Korea: annual report on the Continuous Quality Improvement program of the Korean Society for Cytopathology for 2018
}

\author{
Yosep Chong ${ }^{1 *}$, Haeyoen Jung ${ }^{2 *}$, Jung-Soo Pyo ${ }^{3}$, Soon Won Hong ${ }^{4}$, Hoon Kyu $\mathrm{Oh}^{5}$, \\ The Committee of Quality Improvement of Korean Society for Cytopathology \\ ${ }^{1}$ Department of Hospital Pathology, College of Medicine, The Catholic University of Korea, Seoul; \\ Department of Pathology, Eone Laboratories, Incheon; \\ ${ }^{3}$ Department of Pathology, Eulji University Hospital, Eulji University School of Medicine, Seoul; \\ ${ }^{4}$ Department of Pathology, Gangnam Severance Hospital, Yonsei University College of Medicine, Seoul; \\ ${ }^{5}$ Department of Pathology, Daegu Catholic University School of Medicine, Daegu, Korea
}

Background: The Korean Society for Cytopathology has conducted the Continuous Quality Improvement program for cytopathology laboratories in Korea since 1995. In 2018 as part of the program, an annual survey of cytologic data was administered to determine the current status of cytopathology practices in Korea. Methods: A questionnaire was administered to 211 cytopathology laboratories. Individual laboratories submitted their annual statistics regarding cytopathology practices, diagnoses of gynecologic samples, inadequacy rates, and gynecologic cytology-histology correlation review (CHCR) data for 2018. In addition, proficiency tests and sample adequacy assessments were conducted using five consequent gynecologic slides. Results: Over 10 million cytologic exams were performed in 2018, and this number has almost tripled since this survey was first conducted in 2004 (compounded annual growth rate of 7.2\%). The number of non-gynecologic samples has increased gradually over time and comprised $24 \%$ of all exams. The overall unsatisfactory rate was $0.14 \%$. The ratio of the cases with atypical squamous cells to squamous intraepithelial lesions accounted for up to 4.24 . The major discrepancy rate of the $\mathrm{CHCR}$ in gynecologic samples was $0.52 \%$. In the proficiency test, the major discrepancy rate was approximately $1 \%$. In the sample adequacy assessment, a discrepancy was observed in $0.1 \%$ of cases. Conclusions: This study represents the current status of cytopathology practices in Korea, illustrating the importance of the Continuous Quality Improvement program for increasing the accuracy and credibility of cytopathologic exams as well as developing national cancer exam guidelines and government projects on the prevention and treatment of cancer.

Key Words: Cytology; Surveys; Statistics; Quality; Accuracy

Received: December 26, 2019 Revised: February 19, 2020 Accepted: February 26, 2020

Corresponding Author: Hoon Kyu Oh, MD, PhD, Department of Pathology, Daegu Catholic University School of Medicine, 33 Duryugongwon-ro 17-gil, Nam-gu, Daegu 42472, Korea

Tel: +82-53-650-4156, Fax: +82-53-650-3456, E-mail: ap501@cu.ac.kr

*Yosep Chong and Haeyoen Jung contributed equally to this work.

The Korean Society for Cytopathology (KSC) has conducted the Continuous Quality Improvement program for cytopathology laboratories in Korea since 1995 [1]. In 1992, the Committee of Quality Improvement of the KSC (CQIKSC) was first founded. In 1995, the standard operating procedures and documents of quality assurance (QA) were enacted, and the first nationwide survey of annual statistics on cytologic exams of all institutions was conducted. In 1996, the first proficiency tests (PTs) and the certification of participating institutions were performed with
100 institutions. Since 2003, all cytopathology laboratories in Korea have been obliged to submit annual statistics and participate in PTs to be certified by the CQIKSC. The number of participating institutions was 148 in 2004 and increased to 211 in 2018. Currently, the certification awarded through the Continuous Quality Improvement program is regarded as an important standard to qualify individual cytopathology laboratories, especially in conjunction with the National Cancer Screening Program that was started in 1999 [1-3]. 
The Continuous Quality Improvement program initially consisted of an annual survey of the statistics on gynecological (GYN) cytologic exams. Recently, the survey has been expanded to cover overall statistics, statistics on the diagnostic category of GYN exams, inadequacy rates, cytology-histology correlation reviews (CHCRs), and the number of discordant cases. PTs were initially performed 2-4 times annually using three slides; however, in 2013, this was adjusted to once annually using five glass slides. Sample adequacy evaluations have been performed with five GYN slides submitted from participating institutions since 2013. Since 2009, six glass slides from each participating institution have been submitted to be used in the PTs for the following years. The statistical analysis of the submitted data has been unofficially performed by CQIKSC to efficiently develop a strategy for quality improvement. Official reports have only been published twice: in 2008 (using data collected before 2007) [1] and 2017 (using data collected before 2016) [4]. A new report using the data collected between 2007 and 2017 is currently being compiled for publication. The Continuous Quality Improvement statistics are very credible and represent the current status of cytopathology practices in Korea [4]. In addition, quality data to support the creation of national policies and strategies in cancer screening are becoming more essential [5]; therefore, CQIKSC has decided to publish the statistics annually.

Thus, we present the results of a nationwide survey on annual statistics from cytologic exams and PTs for 2018.

\section{MATERIALS AND METHODS}

\section{The Continuous Quality Improvement program by CQIKSC}

As mentioned earlier, the annual Continuous Quality Improvement program consists of four parts: 1, a survey of the statistics on the cytologic exams performed in the last year; 2, a PT using five glass slides; 3 , a sample adequacy evaluation of five GYN glass slides submitted by the participating institutions; and 4 , submission of six candidate slides by the participating institutions to be used in the PTs of the following years.

\section{Annual survey of cytopathology statistics}

A nationwide survey was conducted by CQIKSC from February 11, 2019, to February 22, 2019. The questionnaire and the written informed consent were collected from 211 medical institutions performing cytopathologic examinations in Korea in 2018. The questionnaire included the statistical data on overall cytologic exams, the case number of the GYN exams according to the diagnostic categories, the GYN sample adequacy, the CHCR results, and the number of discordant cases according to the discordant assessment criteria. The diagnostic concordance between the cytologic and corresponding histologic examination of the uterine cervix or endometrium was categorized as either concordant (category $\mathrm{O}$ ) or one of three discordant categories: category A (minimal clinical impact), category B (minor clinical impact), or category $C$ (major clinical impact). The criteria for CHCR were developed by the individual institutes according to the internal guidelines for laboratory QA. The discordant assessment criteria for PT by CQIKSC were provided to each institute as a reference for the criteria for CHCR (Tables 1-4).

The participating institutions were categorized into three groups: university hospitals, general hospitals, and commercial laboratories. The overall cytologic exam statistics were analyzed by category. The sample categories were as follows: GYN, fineneedle aspiration (FNA), and non-GYN/non-FNA sample exams including urine, body fluids, respiratory tract samples (sputum, bronchial washing, brushing, bronchioloalveolar lavage, etc.), cerebrospinal fluid, etc. Endoscopic bronchial ultrasonography-assisted aspiration cytology samples were classified as FNA samples other than body fluids. The cystic fluids derived from anatomical body cavities, such as the pleural, peritoneal, or pericardial cavities, were classified as body fluids although they were obtained by needle aspiration.

Table 1. Discordance assessment criteria for gynecologic samples, squamous lesions

\begin{tabular}{lcccccc}
\hline \multirow{2}{*}{ Original diagnosis } & \multicolumn{5}{c}{ Submitted diagnosis } \\
\cline { 2 - 6 } & Negative & ASC-US & ASC-H & L-SIL & H-SIL & Carcinoma \\
\hline Negative & O & A & B & A & B & C \\
ASC-US & A & O & A & O & A & B \\
ASC-H & B & A & O & A & O & B \\
L-SIL & A & A & A & O & A & B \\
H-SIL & B & B & A & A & O & A \\
Carcinoma & C & B & B & B & A & O \\
\hline
\end{tabular}

ASC-US, atypical squamous cells of undetermined significance; ASC-H, atypical squamous cells, cannot exclude H-SIL; L-SIL, low-grade squamous intraepithelial lesion; H-SIL, high-grade squamous intraepithelial lesion. 
Table 2. Discordance assessment criteria for gynecologic samples, glandular lesions

\begin{tabular}{lccccc}
\hline \multirow{2}{*}{ Original diagnosis } & \multicolumn{5}{c}{ Submitted diagnosis } \\
\cline { 2 - 6 } & Negative & AGC & AGC, favor neoplastic & Endocervical Als & Adenocarcinoma \\
\hline Negative & O & A & B & B & B \\
AGC & A & O & A & A & B \\
AGC, favor neoplastic & B & A & O & O & A \\
Endocervical AIS & B & B & A & A & A \\
Adenocarcinoma & C & B & A & \\
\hline
\end{tabular}

AGC, atypical glandular cells; AIS, adenocarcinoma in situ.

Table 3. Discordance assessment criteria for thyroid fine-needle aspiration

\begin{tabular}{|c|c|c|c|c|c|c|c|c|c|}
\hline \multirow[b]{2}{*}{ Submitted diagnosis } & \multicolumn{9}{|c|}{ Original diagnosis } \\
\hline & $\begin{array}{l}\text { Benign, } \\
\text { c/w a } \\
\text { benign } \\
\text { follicular } \\
\text { nodule }\end{array}$ & $\begin{array}{c}\text { Benign, } \\
\text { c/w chronic } \\
\text { lymphocytic } \\
\text { (Hashimoto's) } \\
\text { thyroiditis }\end{array}$ & $\begin{array}{c}\text { Benign, } \\
\text { c/w } \\
\text { granulomatous } \\
\text { (subacute) } \\
\text { thyroiditis }\end{array}$ & $\begin{array}{l}\text { Follicular } \\
\text { lesion, } \\
\text { conventional } \\
\text { type }\end{array}$ & $\begin{array}{l}\text { Follicular } \\
\text { lesion, } \\
\text { Hurthle cell } \\
\text { (oncocytic } \\
\text { type) }\end{array}$ & $\begin{array}{l}\text { Papillary } \\
\text { carcinoma }\end{array}$ & $\begin{array}{l}\text { Poorly } \\
\text { differentiated } \\
\text { carcinoma }\end{array}$ & $\begin{array}{l}\text { Medullary } \\
\text { carcinoma }\end{array}$ & $\begin{array}{l}\text { Undifferentiated } \\
\text { (anaplastic) } \\
\text { carcinoma }\end{array}$ \\
\hline $\begin{array}{l}\text { Benign, c/w a benign } \\
\text { follicular nodule }\end{array}$ & 0 & $A$ & $\mathrm{~A}$ & $\mathrm{~B}$ & $\mathrm{~B}$ & $\mathrm{C}$ & $\mathrm{C}$ & $\mathrm{C}$ & $\mathrm{C}$ \\
\hline $\begin{array}{l}\text { Benign, c/w chronic } \\
\text { lymphocytic (Hashimoto's) } \\
\text { thyroiditis }\end{array}$ & $A$ & 0 & $A$ & B & B & C & C & C & C \\
\hline $\begin{array}{l}\text { Benign, c/w granulomatous } \\
\text { (subacute) thyroiditis }\end{array}$ & $A$ & $A$ & 0 & B & B & C & C & C & C \\
\hline Benign, other & $A$ & $A$ & $A$ & $\mathrm{~B}$ & $\mathrm{~B}$ & C & C & C & C \\
\hline AUS or FLUS & $A$ & $A$ & $A$ & $A$ & $A$ & $B$ & $B$ & $B$ & $B$ \\
\hline $\begin{array}{l}\text { Follicular lesion, } \\
\text { conventional type }\end{array}$ & B & B & B & 0 & A & A & B & B & B \\
\hline $\begin{array}{l}\text { Follicular lesion, Hurthle cell } \\
\text { (oncocytic type) }\end{array}$ & B & B & B & B & 0 & A & $B$ & B & $B$ \\
\hline $\begin{array}{l}\text { Suspicious for papillary } \\
\text { carcinoma }\end{array}$ & C & C & C & B & B & O & B & B & B \\
\hline $\begin{array}{l}\text { Suspicious for poorly } \\
\text { differentiated carcinoma }\end{array}$ & C & C & C & B & B & B & 0 & B & B \\
\hline $\begin{array}{l}\text { Suspicious for medullary } \\
\text { carcinoma }\end{array}$ & C & C & C & B & B & B & $B$ & 0 & B \\
\hline $\begin{array}{l}\text { Suspicious for } \\
\text { undifferentiated carcinoma }\end{array}$ & C & C & C & B & B & B & $B$ & $B$ & O \\
\hline Suspicious for lymphoma & C & $\mathrm{C}$ & $\mathrm{C}$ & $\mathrm{B}$ & $\mathrm{B}$ & $B$ & $B$ & $B$ & B \\
\hline $\begin{array}{l}\text { Suspicious for malignancy, } \\
\text { other }\end{array}$ & C & C & C & B & B & $A$ & B & B & B \\
\hline Papillary carcinoma & C & C & $\mathrm{C}$ & $A$ & $A$ & 0 & $A$ & $A$ & $A$ \\
\hline $\begin{array}{l}\text { Poorly differentiated } \\
\text { carcinoma }\end{array}$ & C & C & C & B & B & $A$ & 0 & A & A \\
\hline Medullary carcinoma & C & C & $\mathrm{C}$ & $\mathrm{B}$ & B & $A$ & $A$ & $\mathrm{O}$ & $A$ \\
\hline $\begin{array}{l}\text { Undifferentiated (anaplastic) } \\
\text { carcinoma }\end{array}$ & C & C & C & $\mathrm{B}$ & B & $A$ & $A$ & A & O \\
\hline Malignant, other & C & C & C & B & B & A & $A$ & A & A \\
\hline
\end{tabular}

$\mathrm{C} / \mathrm{w}$, consistent with; AUS, atypia of undetermined significance; FLUS, follicular lesion of undetermined significance.

\section{Proficiency test}

The second part of the Continuous Quality Improvement program, the PT, was performed in 209 medical institutions from May 3, 2019, to May 25, 2019, using a total of 1,045 glass slides. Five glass slides (2 GYN slides, 1 body fluid or urine, 2 respiratory tract sample or FNA slides) were dispatched to the participating institutions by parcel post. The candidate cases for PT, along with their cytologic diagnoses and the corresponding histologic diagnoses, were collected from the participating institutions in 2015 and 2016. The cases were reviewed by members of the CQIKSC and their eligibility for PT was confirmed. The diagnosis submitted by participating institutions was based 
Table 4. Discordance assessment criteria for body fluid, urine, and other fine-needle aspiration samples

\begin{tabular}{lccccc}
\hline \multirow{2}{*}{ Original diagnosis } & \multicolumn{5}{c}{ Submitted diagnosis } \\
\cline { 2 - 6 } & Negative or benign & Atypical, favor reactive & Atypical, favor neoplastic & Malignant & Malignant, but different diagnosis \\
\hline Benign & $\mathrm{O}$ & $\mathrm{A}$ & $\mathrm{B}$ & $\mathrm{C}$ & $\mathrm{C}$ \\
Atypical, favor reactive & $\mathrm{A}$ & $\mathrm{O}$ & $\mathrm{A}$ & $\mathrm{B}$ & $\mathrm{B}$ \\
Atypical, favor neoplastic & $\mathrm{B}$ & $\mathrm{A}$ & $\mathrm{O}$ & $\mathrm{A}$ & $\mathrm{A}$ \\
Malignant & $\mathrm{C}$ & $\mathrm{B}$ & $\mathrm{A}$ & $\mathrm{O}$ & $\mathrm{A}$ \\
\hline
\end{tabular}

on the Bethesda system [6] for GYN samples and on the thyroid Bethesda system [7] for thyroid FNA samples. The submitted diagnoses were evaluated using the discordance assessment criteria (Tables $1-4$ ), and the diagnostic concordance was categorized as either concordant (category $\mathrm{O}$ ) or as one of three discordant categories: category A (minimal clinical impact), category $\mathrm{B}$ (minor clinical impact), or category C (major clinical impact). The criteria for PT have been developed and modified by CQIKSC based on the potential clinical impact in relation to the clinical treatment guidelines.

\section{Sample adequacy assessment}

The third part of the program was the sample adequacy assessment. Each participating institution was asked to submit five GYN glass slides of any consequent number and the corresponding reported adequacy that were diagnosed in each institution on March 5, 2018. They were submitted to the CQIKSC from September 10, 2018, to September 21, 2018, and the sample adequacy was reevaluated by the members of the CQIKSC.

\section{Submission of samples for the QA program}

For the final part of the program, each participating institution was asked to submit six glass slides ( 2 GYN, 2 non-GYN, and 2 FNA) with confirmed cytologic diagnoses and the corresponding histologic diagnoses from November 26, 2018, to December 7, 2018. The eligibility of the collected samples for the PT was evaluated by the members of the CQIKSC, and eligible samples were archived to be used in the PT in the following years.

\section{Statistical analysis}

The correlation between total case numbers, liquid-based preparation (LBP) coverage, atypical squamous cells to squamous intraepithelial lesions ratio (ASC/SIL ratio) of participant institutions in 2018 was done using Pearson correlation analysis with Microsoft Excel 14.0.7237.5000, Microsoft Co. (Redmond, CA, USA).

\section{RESULTS}

\section{Participating institutions}

Responses were obtained from all 211 medical institutions, including 83 university hospitals (39.3\%), 84 general hospitals (39.8\%), and 44 commercial laboratories (20.8\%) (Fig. 1). The number of participating institutions steadily increased from 148 in 2004 to 211 in 2018. In particular, the number of commercial laboratories significantly increased from $25(14.6 \%)$ in 2009 to 44 (20.8\%) in 2018, while the number of general and university hospital laboratories slightly increased.

\section{Overall statistics}

The total number of cytopathologic examinations performed in 2018 was $10,057,839$; this number was more than triple the number of examinations performed in 2004 (2,891,867, compounded annual growth rate: $7.2 \%$ ) (Fig. 1). The number of cytologic exams performed was 1,695,625 in university hospitals (16.9\%), 732,880 in general hospitals (7.3\%), and 7,629,334 in commercial laboratories (75.9\%). In 2018, commercial laboratories only comprised approximately $20 \%$ of the total institutions but performed over $75 \%$ of the total examinations (Supplementary Fig. S1). In 2015, commercial laboratories comprised $17.5 \%$ of the participating institutions (36 out of 206) and performed 5,717,336 out of 8,284,952 exams (69.0\%), illustrating a significant increase of the segment share $(69.0 \%$ to $75.9 \%)$ and the number of institutions (17.5\% to 20.8\%). In 2018, the average number of cytologic exams was 20,429 in university hospitals, 8,724 in general hospitals, and 173,393 in commercial laboratories. In 2015, the average number of cytologic exams was 19,320 in university hospitals, 11,080 in general hospitals, and 158,814 in commercial laboratories, illustrating a significant increase in the number of exams in university hospitals and commercial laboratories and a significant decrease in the number of exams in general hospitals.

\section{GYN and non-GYN samples}

In 2018, the total number of GYN samples was 7,641,281 (76.0\%), and the total number of non-GYN samples was 


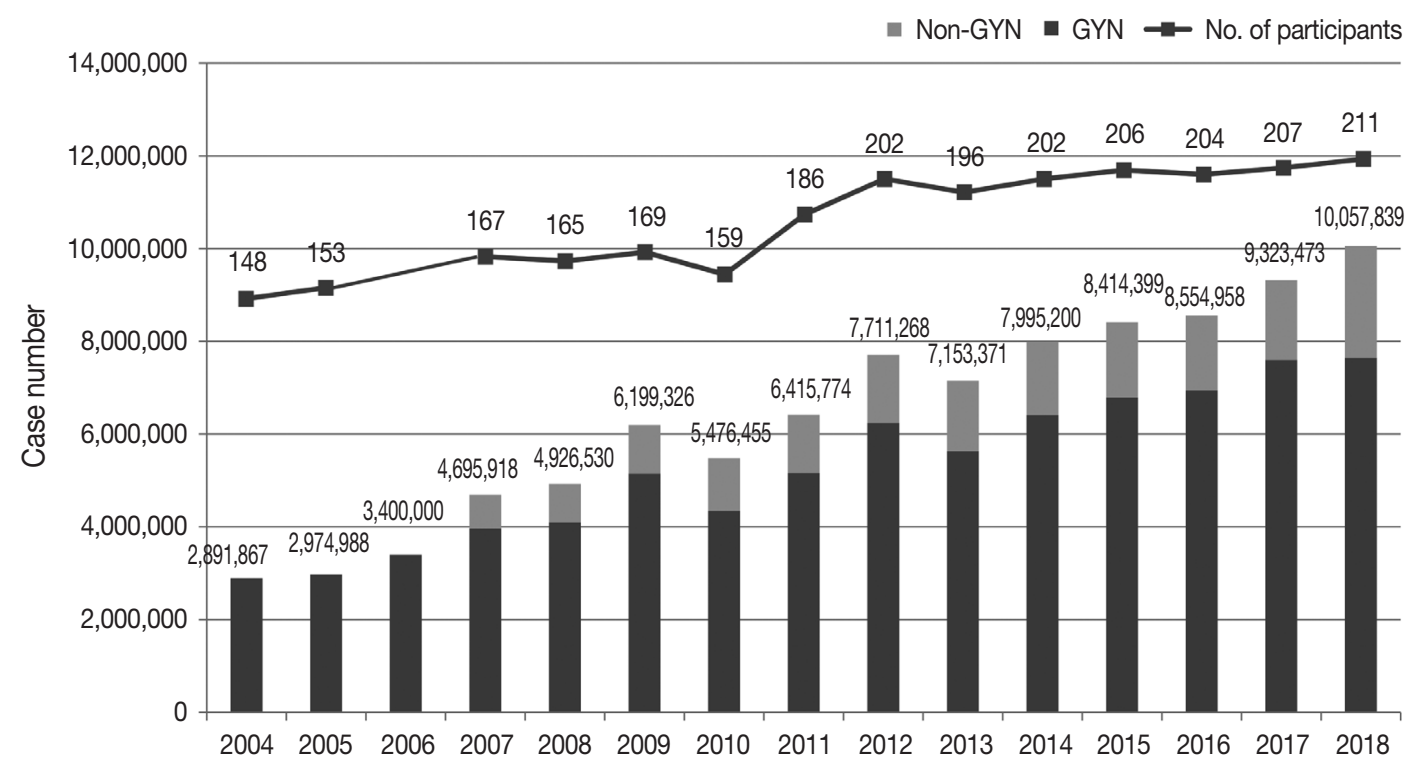

Fig. 1. Overall statistics of cytopathology exams from 2004 to 2018. GYN, gynecologic samples; Non-GYN, non-gynecologic samples.

2,416,558 (24.0\%). The percentage of non-GYN samples gradually increased from $14 \%$ in 2007 to $24.0 \%$ in 2018 . The majority (approximately $80.9 \%$ ) of the GYN samples were analyzed in commercial laboratories ( $\mathrm{n}=6,181,796)$, while only $6.7 \%$ and $12.5 \%$ were processed by general and university hospitals, respectively. The proportion of GYN samples analyzed by commercial laboratories significantly increased from $58.0 \%$ in 2004 and $74.2 \%$ in 2015 to $80.9 \%$ in 2018; however, from 2015 to 2018 , this number was similar in university hospitals $(13.8 \%$ and $12.5 \%)$ and significantly decreased in general hospitals $(11.1 \%$ to $6.7 \%)$. The proportion of non-GYN samples was highest in university hospitals (44\%), followed by general hospitals (31\%) and commercial laboratories (19\%).

The primary types of non-GYN samples were body fluids ( $\mathrm{n}=$ $1,664,313,68.9 \%)$, followed by urine $(\mathrm{n}=431,749,17.9 \%)$ and FNA ( $\mathrm{n}=320,496,13.3 \%)$. The majority of the body fluids were obtained from the respiratory system (e.g., sputum, bronchial washing, or bronchial brushing, $\mathrm{n}=1,508,676,90.6 \%$ ) (Fig. $2 A$ ). Most of the FNA samples were taken from the thyroid ( $\mathrm{n}=$ $225,511,70.4 \%)$. The FNA and urine samples were more common in the university (17.4\% and $30.6 \%$, respectively) and general hospitals (18.9\% and $24.2 \%$, respectively), while body fluids from the respiratory tract comprised the majority of the commercial laboratory samples (79.4\%) (Fig. 2B).

\section{Conventional and LBP cytology}

Of all the samples, 8,030,418 (79.8\%) samples were prepared by conventional smear, and 2,027,421 (20.2\%) samples were prepared by LBP. The LBP method was used in $19.5 \%$ of the GYN ( $\mathrm{n}=1,493,582)$ and $22.1 \%$ of the non-GYN samples ( $\mathrm{n}=$ $533,839)$, including $44.4 \%$ of the urine $(\mathrm{n}=191,769), 43.6 \%$ of the FNA ( $\mathrm{n}=139,599)$, and $12.1 \%$ of the body fluid ( $\mathrm{n}=$ 202,471) samples (Fig. 3A). The LBP coverage of the GYN samples slightly decreased from 2017 to 2018 (20.3\% to 19.5\%). The LBP coverage of the non-GYN samples also decreased from 2017 to 2018 (25.2\% to 22.1\%), although the coverage was significantly increased in the FNA and urine subsets among the non-GYN samples. This indirectly suggests that from 2017 to 2018 a relatively high increase of GYN and body fluid samples were prepared by conventional methods (Fig. 3A). The LBP coverage of the GYN samples increased from 2017 to 2018 in both university and general hospitals, while it decreased in commercial laboratories (Fig. 3B). This pattern was similar in the non-GYN samples; the LBP coverage decreased only in commercial laboratories in 2018 (Fig. 3C). Among the subsets of the non-GYN samples, the LBP coverage generally increased in the FNA and urine samples of all institutions, while it only decreased in the body fluid samples of the commercial laboratories. (Fig. 3D-F). Chronologically, the LBP coverage in the GYN samples increased from $7.6 \%$ in 2004, reached a peak of $29.0 \%$ in 2012, and decreased slightly to $19.5 \%$ in 2018 (Fig. 3G).

\section{Distribution of the GYN sample cytologic diagnoses}

The cytologic diagnoses percentages of the GYN samples are summarized in Table 5 . The percentage of the samples with "unsatisfactory adequacy" was $0.14 \%$ in 2018 . The overall per- 

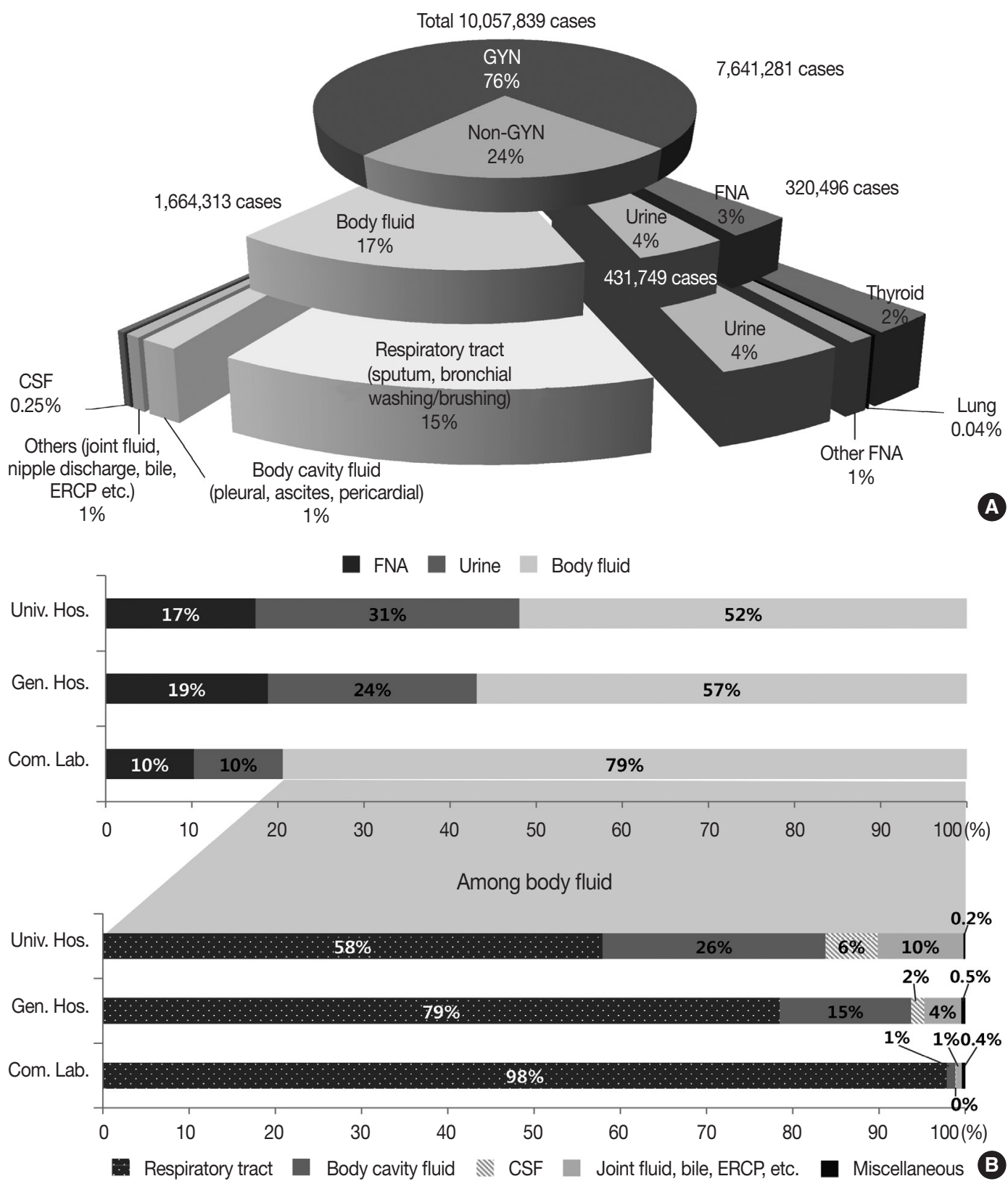

Fig. 2. Number and proportion of cytopathology exams according to types of sample (A) and institution (B). GYN, gynecologic samples; Non-GYN, non-gynecologic samples; FNA, fine-needle aspiration; CSF, cerebrospinal fluid; ERCP, endoscopic retrograde cholangiopancreatography; Univ. Hos., university hospitals; Gen. Hos., general hospitals; Com. Lab., commercial laboratories.

centage of the "negative" samples was $95.29 \%$. The percentage of "atypical squamous cells of undetermined significance" (ASC-US) and "atypical squamous cells-cannot exclude highgrade squamous intraepithelial lesion" were $3.45 \%$ and $0.19 \%$, respectively. The percentage of "low-grade squamous intraepithelial lesion" and "high-grade squamous intraepithelial lesion" were $0.65 \%$ and $0.19 \%$, respectively. The ratio of ASC-US to squamous intraepithelial lesion (SIL) was 4.25 in 2018. Compared to 2017, the percentage of ASC-US increased from $3.47 \%$ to
$3.69 \%$, and the percentage of SIL decreased from $0.91 \%$ to $0.87 \%$.

Although the total number of GYN samples increased significantly from 5,640,080 in 2012 to 7,706,455 in 2018 as the coverage of the National Cancer Screening Program increased, the total number of SIL and cancer slightly decreased from 71,722 in 2012 to 67,063 in 2018 and 2,847 in 2012 to 2,042 in 2018, respectively (Fig. 4A). In contrast, the atypical squamous cell (ASC) percentage increased slightly from $3.03 \%$ in 2012 to $3.69 \%$ in 
2018. As a result, the ASC/SIL ratio increased from 2.98 in 2012 to 4.24 in 2018. With regard to institutions, the ASC/SIL ratio was steadily maintained at approximately 1.8 in university hos-
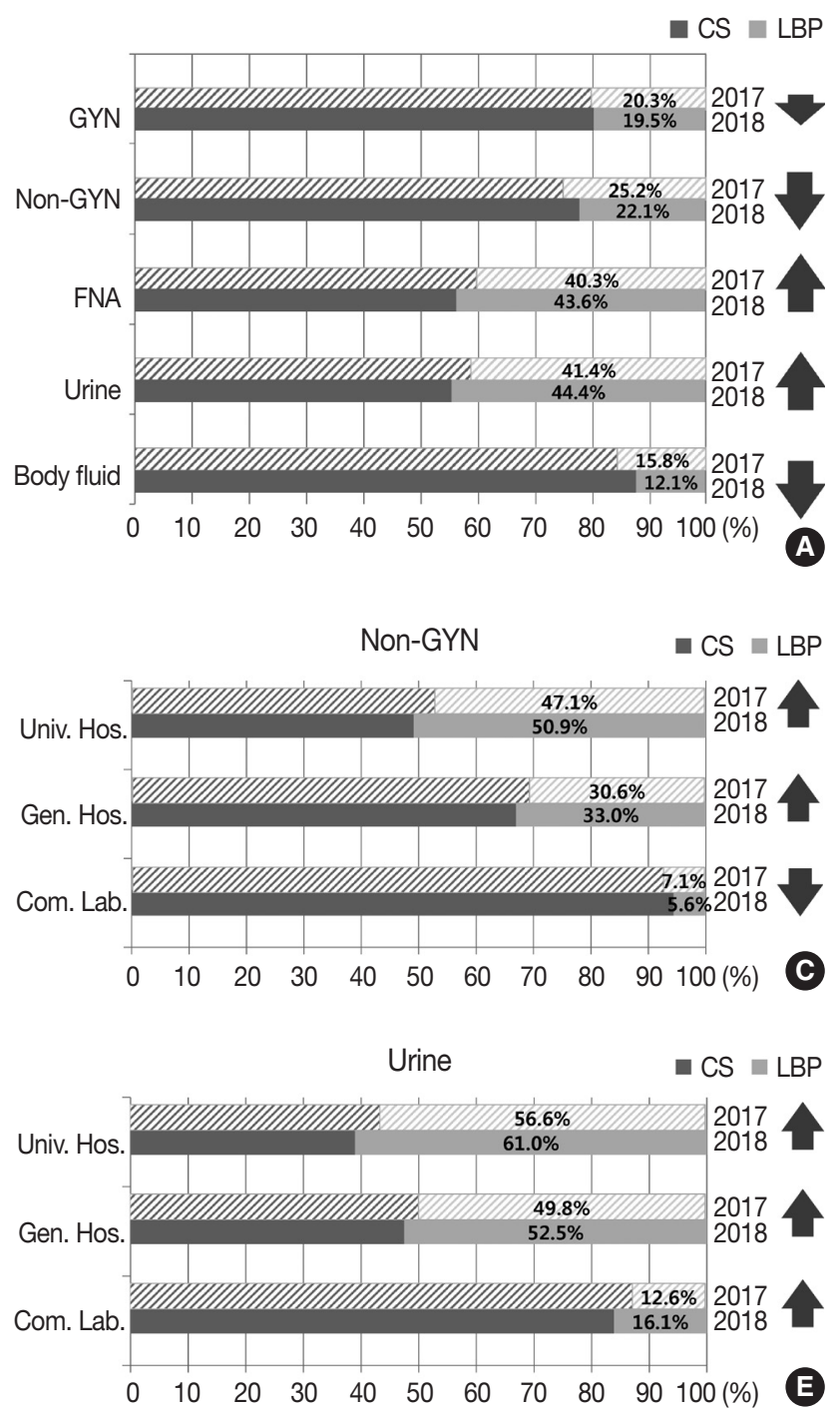

- CS $\square \mathrm{LBP}$

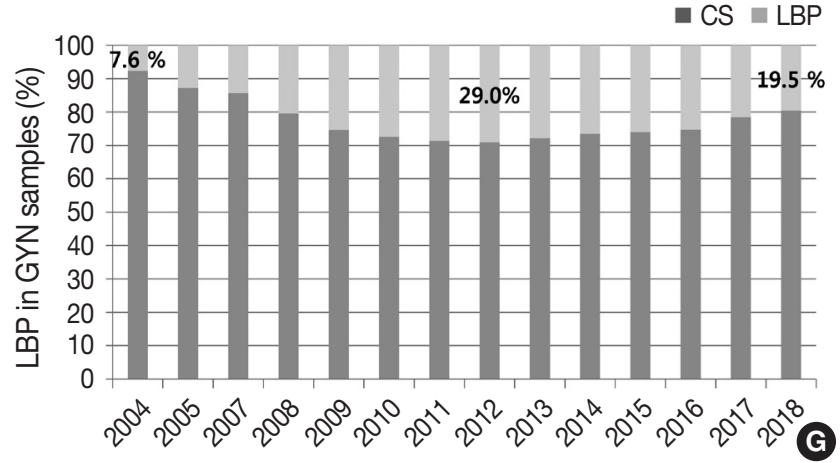

Fig. 3. Proportion of conventional smear (CS) and liquid-based preparation (LBP) cytology. Change in proportion between 2017 and 2018 of all samples (A), gynecologic samples (GYN) (B), non-gynecologic samples (Non-GYN) (C), fine-needle aspiration (FNA) (D), urine (E), and body fluid (F). (G) Proportion of CS and LBP cytology of gynecologic samples from 2004 to 2018. Univ. Hos., university hospitals; Gen. Hos., general hospitals; Com. Lab., commercial laboratories. pitals and 2.5 in general hospitals; however, it has continuously increased in commercial laboratories from 3.68 in 2012 to 5.65 in 2018 (Fig. 4B). A correlation analysis using the data from all
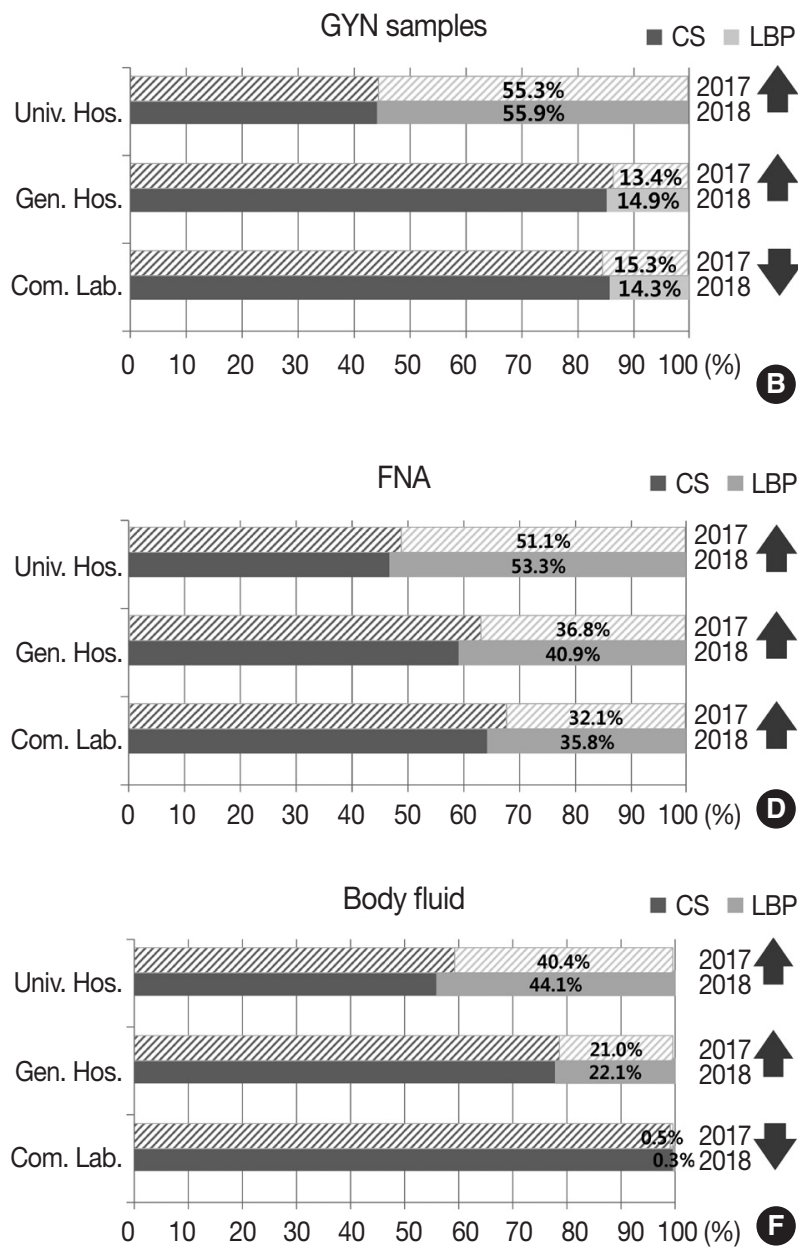
Table 5. Distribution of the gynecologic sample cytologic diagnoses

\begin{tabular}{lrc}
\hline \multicolumn{1}{c}{ Cytologic diagnosis } & 2017 & 2018 \\
\hline Unsatisfactory & 0.24 & 0.14 \\
Negative (reactive cellular change, inflammation, & 95.10 & 95.29 \\
atrophy, etc.) & 3.51 & 3.64 \\
ASC & 3.31 & 3.45 \\
ASC-US & 0.20 & 0.19 \\
ASC-H & 0.05 & 0.05 \\
AGC & 0.01 & 0.01 \\
AGC, favor neoplastic & 0.70 & 0.65 \\
L-SIL & 0.20 & 0.19 \\
H-SIL & 0.02 & 0.02 \\
Squamous cell carcinoma & 0.00 & 0.01 \\
Adenocarcinoma & 3.82 & 4.25 \\
ASC/SIL ratio & & \\
\hline
\end{tabular}

ASC, atypical squamous cells; ASC-US, atypical squamous cells of uncertain significance; ASC-H, atypical squamous cells, cannot exclude H-SIL; AGC, atypical glandular cells; L-SIL, low-grade squamous intraepithelial lesion; H-SIL, high-grade squamous intraepithelial lesion; ASC/SIL ratio, atypical squamous cells/squamous intraepithelial lesion ratio.

211 institutions showed that the laboratories with more cases tended to use less LBP and report a higher ASC/SIL ratio, although these findings were not statistically significant (Fig. 4C, D). Moreover, the laboratories that used more LBP tended to report significantly lower ASC/SIL ratios (Fig. 4E).

\section{CHCR for the GYN cytology}

As part of the internal quality control $(\mathrm{QC})$ program, each institution was asked to compare the diagnoses of the cytologic and histologic samples of the same individual whenever possible and to document the degree of discordance between the cytologic and histologic diagnoses according to the institutional criteria. Of 69,808 cases, 60,823 cases showed concordant results between the cytologic and histologic diagnoses (87.1\%) (Fig. 5A). Discordance with minimal and minor clinical impact (categories $\mathrm{A}$ and B) were found in 6,555 and 2,301 cases, respectively (9.4\% and 3.3\%) (Fig. 5B). Discordance with major clinical impact (category C) was found in 361 cases $(0.52 \%)$ (Fig. 5B). Over the past 15 years, while an increasing number of cases have been compared, the discordant rate has been steadily maintained at approximately $15 \%$ (Fig. 5A). However, the rates of discordance with minor and major clinical impact (categories B and C) have markedly decreased from $4.40 \%$ and $1.5 \%$ in 2003 to $3.30 \%$ and $0.52 \%$ in 2018 , respectively (Fig. 5 B).

\section{Adequacy of GYN samples}

The percentage of the GYN samples with unsatisfactory adequacy in each institution was collected as a part of the annual survey. The overall unsatisfactory rate was $0.14 \%$ in 2018 and
$0.24 \%$ in 2017 . It was $0.45 \%$ in university hospitals, $0.44 \%$ in general hospitals, and $0.07 \%$ in commercial laboratories in 2018 .

\section{Proficiency test}

The PT using 1,045 dispatched glass slides showed 84.6\% overall concordance (category O), $12.2 \%$ discordance with minimal clinical impact (category A), 2.2\% discordance with minor clinical impact (category B), and $0.95 \%$ discordance with major clinical impact (category C) (Fig. 6A). The concordance rates reported by the institutions were $86.6 \%$ in university hospitals, $85.9 \%$ in general hospitals, and $78.1 \%$ in commercial laboratories; discordance with major clinical impact (category C) was $1.0 \%$ in university hospitals, $1.2 \%$ in general hospitals, and $0.5 \%$ in commercial laboratories (Fig. 6A). Of the 420 GYN cytology cases, the overall concordance rate was $75.2 \%$, minimal discordance (category A) was $21.0 \%$, minor discordance (category B) was 2.8\%, and major discordance (category C) was $0.5 \%$ (Fig. 6B). Concordance reported by the institutions was $77.4 \%, 77.6 \%$, and $67.9 \%$ in university hospitals, general hospitals, and commercial laboratories, respectively. Major discordance (category $\mathrm{C}$ ) was $0.6 \%, 0.6 \%$, and $0.0 \%$ in the university hospitals, general hospitals, and commercial laboratories, respectively (Fig. 6B). Of the 164 thyroid FNA cases, the overall concordance was $95.7 \%$, and the major discordance was $1.2 \%$ (Fig. 6C). The concordance rates by institution were similar in the university hospitals (98.5\%), general hospitals (95.4\%), and commercial laboratories (90.9\%). Major discordance was found in only two cases $(3.1 \%)$ in the general hospitals (Fig. 6C). Of the 300 body fluid cases, the overall concordance was $91.0 \%$ and the major discordance rate was $1.0 \%$ (Fig. 6D). The concordance rate was $92.4 \%, 92.6 \%$, and $85.0 \%$ in the university hospitals, general hospitals, and commercial laboratories, respectively. Major discordance was found in one case in each institution $(0.8 \%, 0.8 \%$, and $1.7 \%$ in university hospitals, general hospitals, and commercial laboratories, respectively) (Fig. 6D). Of the 108 urine cytology cases, the overall concordance rate was $85.2 \%$, and the major discordance rate was $1.9 \%$ (Fig. 6E). The concordance rate was $86.0 \%, 89.1 \%$, and $73.7 \%$ in the university hospitals, general hospitals, and commercial laboratories, respectively. Major discordance was found in one case in the general hospitals and in the commercial laboratories (2.2\% and 5.3\%, respectively) (Fig. 6E). Among 55 other FNA cases, the overall concordance rate was $83.6 \%$, and the major discordance rate was $5.5 \%$ (Fig. 6F). The concordance rate was $88.9 \%, 78.3 \%$, and $85.7 \%$ in the university hospitals, general hospitals, and commercial laboratories, respectively. Major 


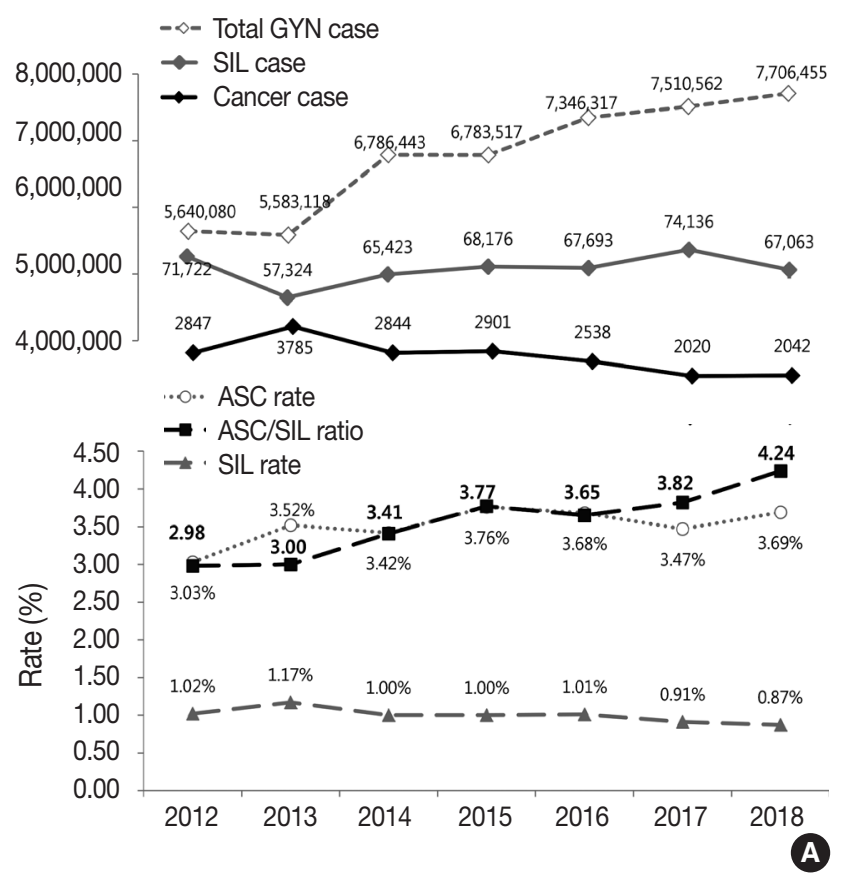

Total case number vs. ASC/SIL ratio (2018)

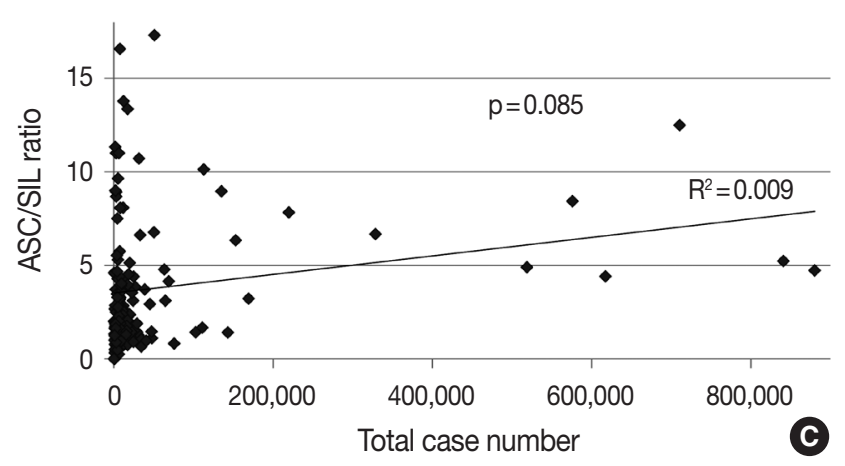

LBP coverage vs. ASC/SIL ratio (2018)

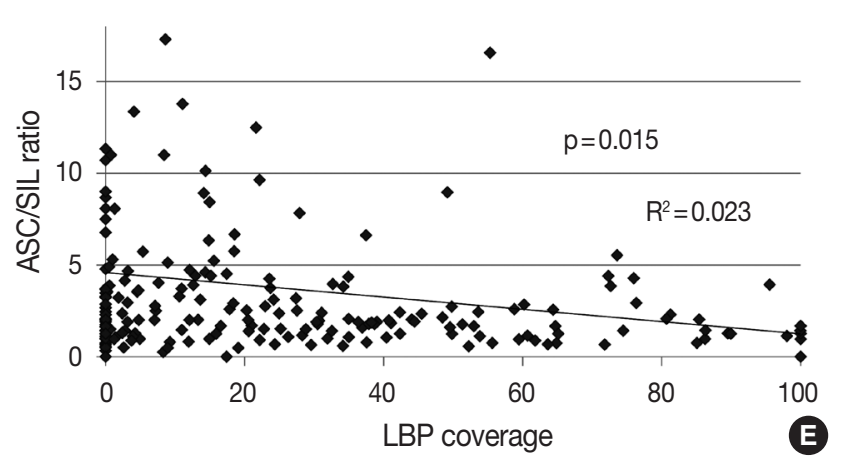

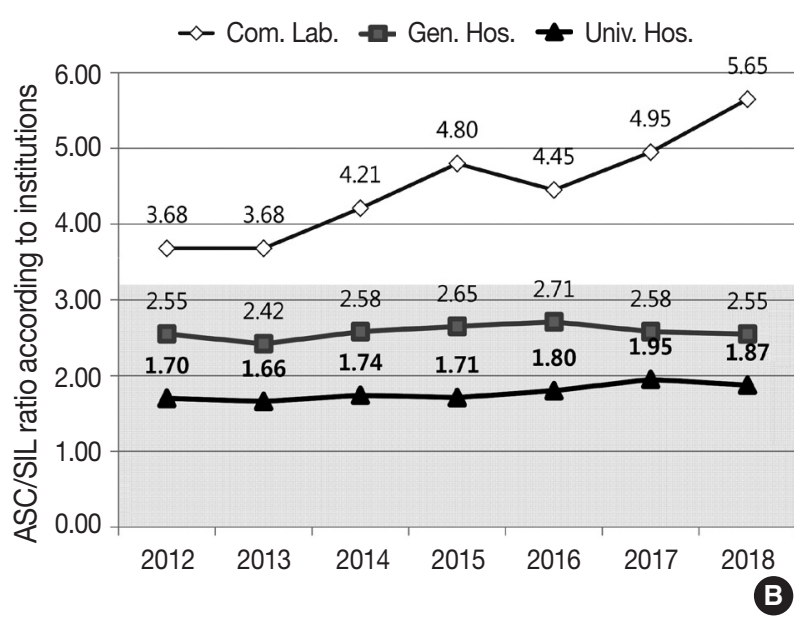

Total case number vs. LBP coverage (2018)

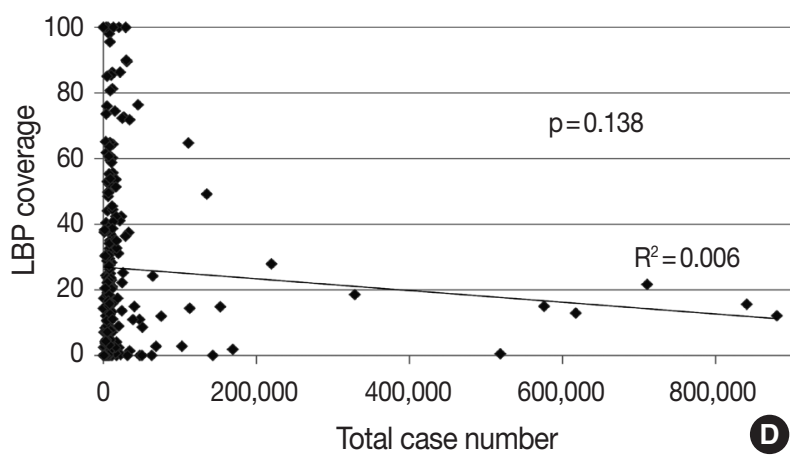

Fig. 4. Trends in gynecologic sample cytologic diagnoses from 2012 to 2018 and correlation analysis according to atypical squamous cells to squamous intraepithelial lesions ratio (ASC/SIL ratio). Trends in the number of total gynecologic (GYN) samples, atypical squamous cells (ASC), squamous intraepithelial lesions (SIL), cervical cancers, and ASC/SIL ratio from 2012 to 2018 (A), ASC/SIL ratio according to institutions (B), correlation of total case number versus liquid-based preparation (LBP) coverage among 211 participating institutions in 2018 (C), correlation of total case number versus ASC/SIL ratio in 2018 (D), correlation of LBP coverage versus ASC/SIL ratio in 2018 (E). Com. Lab., commercial laboratories; Gen. Hos., general hospitals; Univ. Hos., university hospitals. 

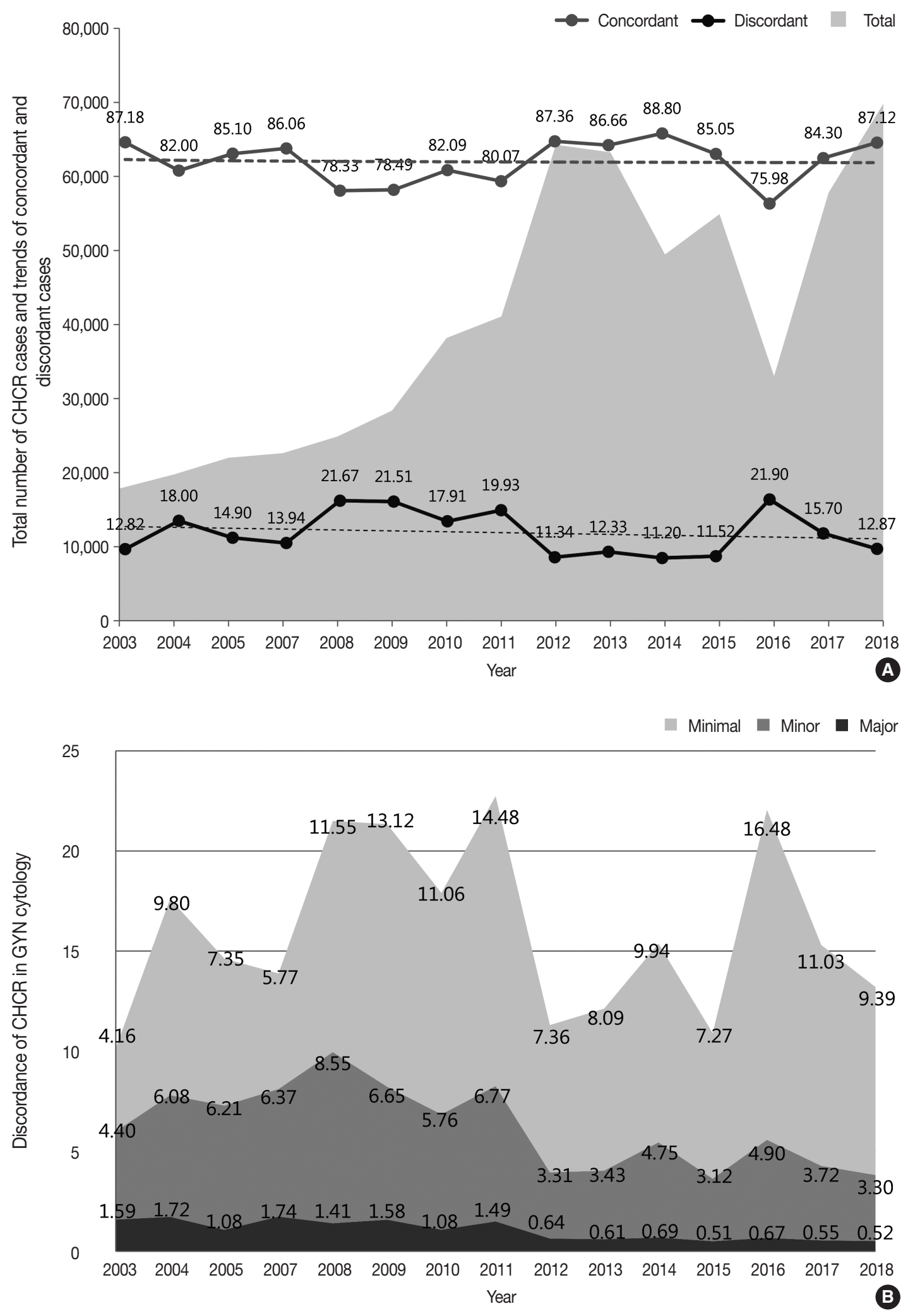

Fig. 5. The results of cytology-histology correlation review (CHCR) from 2003 to 2018. (A) Total number of CHCR cases and trends of the proportions of concordant (category O) and discordant cases. (B) Trends in discordant cases with minimal (category A), minor (category B), and major (category C) clinical impact. GYN, gynecologic samples. 


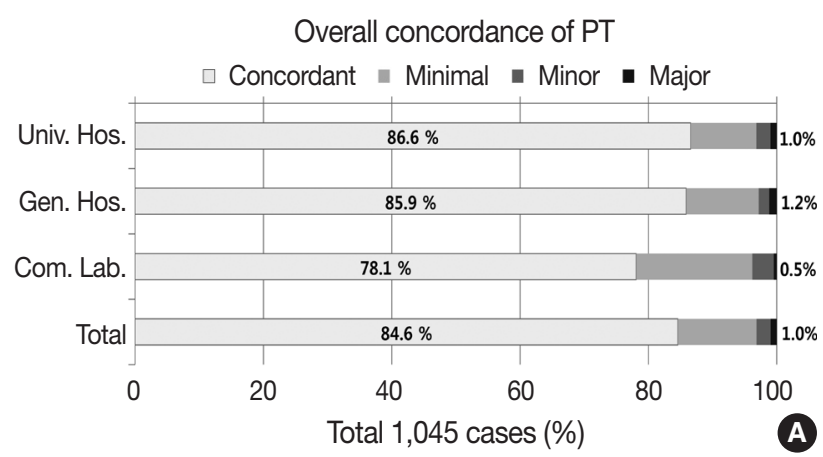

Thyroid FNA

$\square$ Concordant_ - Minimal = Minor - Major

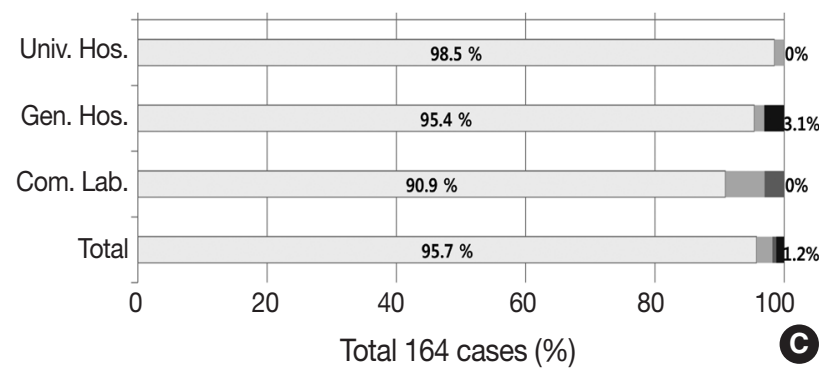

Urine

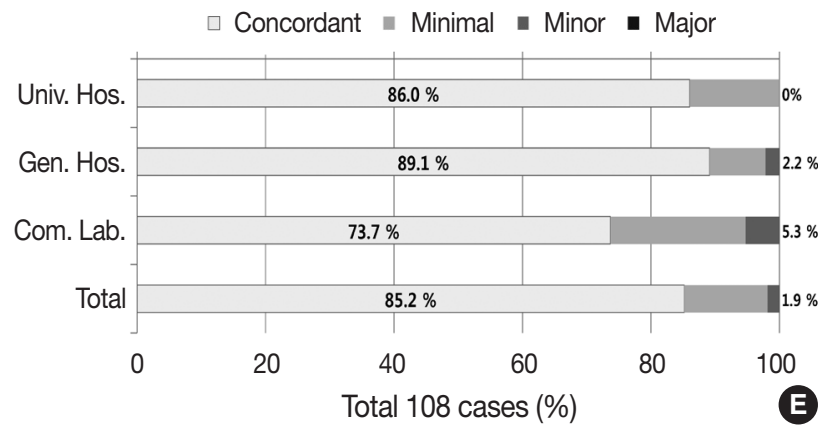

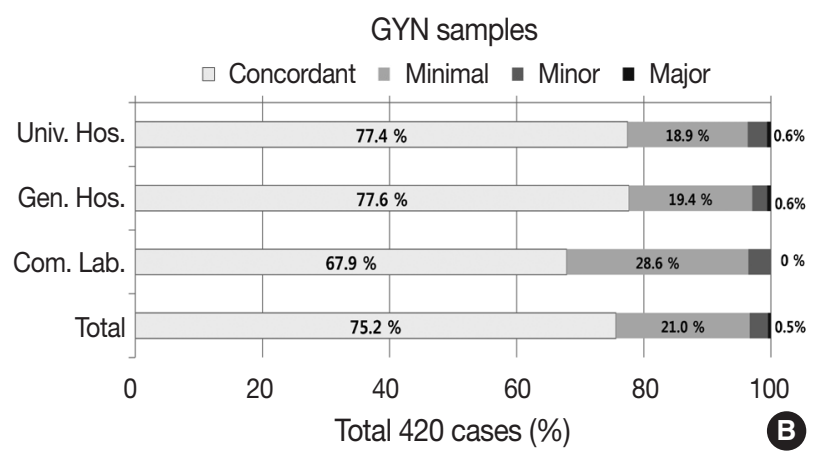

Body fluid

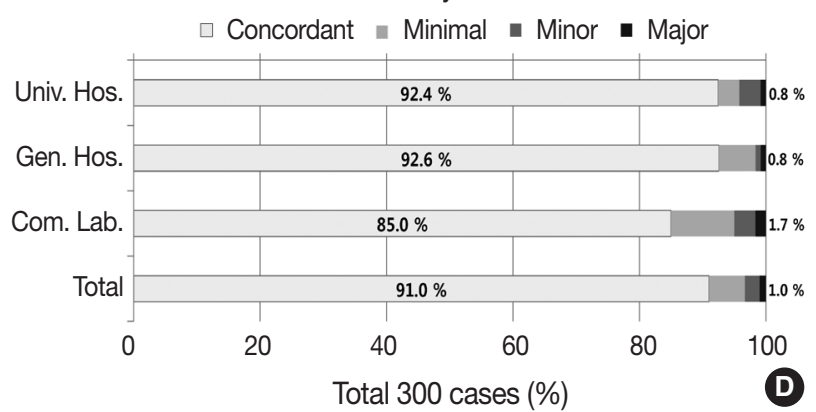

Other FNA

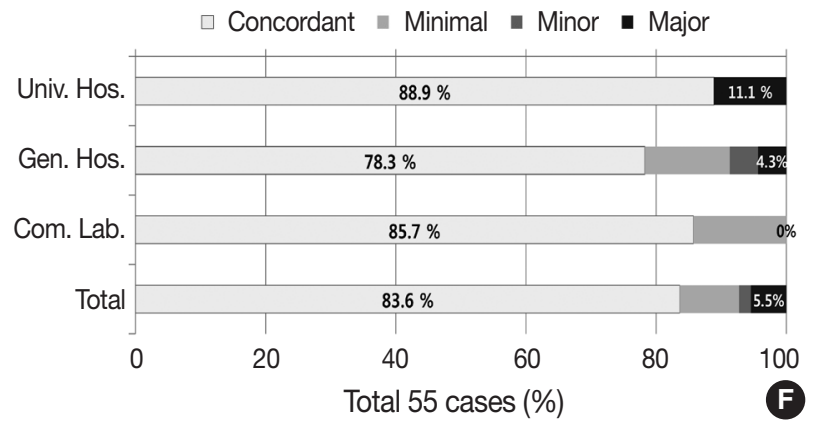

Fig. 6. Proficiency test (PT) results according to institutions in 2018. Overall concordance of PT (A), and concordance of PT in gynecologic samples (B), thyroid fine-needle aspiration (FNA) cytology samples (C), body fluid samples (D), urine (E), and other FNA samples (F). GYN, gynecologic samples; Univ. Hos., university hospitals; Gen. Hos., general hospitals; Com. Lab., commercial laboratories.

discordance was found in two cases and one case in the university and general hospitals, respectively (11.1\% and 4.3\%, respectively) (Fig. 6F).

\section{Sample adequacy assessment}

A total of 193 participating institutions submitted a total of 965 GYN slides of consequent numbers $(5$ slides from each institution) and their reported adequacy. The sample adequacy assessments reevaluated by the members of the CQIKSC and the reported adequacy of the institutions in all cases were concordant.

\section{Submission of samples for the next QA program}

A total of 182 participating institutions submitted 961 glass slides with confirmed cytologic diagnoses and corresponding histologic diagnoses.

\section{DISCUSSION}

The key findings of this study are summarized as follows: 1) the total number of cytopathologic exams is continuously increasing, and the proportion of non-GYN samples is gradually increasing over time; 2) the number of cytopathologic exams processed by commercial laboratories is increasing; 3) the LBP coverage is in- 
creasing in all samples except GYN and body fluid samples processed by commercial laboratories; 4) the total number of GYN exams is increasing, but the number of cancer cases is decreasing; 5) the ASC/SIL ratio is increasing (the ASC percentage is increasing while the SIL percentage is decreasing); 6) the high LBP coverage seems to be lowering the ASC/SIL ratio; 7) the major discordance rate found by the CHCR (internal QC assessment) is decreasing over time; 8) the unsatisfactory rate in GYN samples is well under control; 9) the average diagnosis concordance rate of the PT (external QC assessment) is approximately $85 \%$ with a major discordance (category $\mathrm{C}$ ) rate of less than $1 \%$; and 10) the concordance rate was highest in thyroid FNA, lower in urine and other FNA, and lowest in GYN cytology.

The total number of cytopathologic exams has increased dramatically to over 10 million exams per year. It has more than tripled from the number of total exams in 2004 with a steady compounded annual growth rate of $7.2 \%$. Furthermore, the growth has not slowed but rather reached a peak. In 2018, an annual average of 47,667 cases was processed by individual laboratories that processed only 19,000 cases in 2004. This seems to be primarily due to the introduction of screening cytologic exams in the National Cancer Screening Program $[1,2,8]$. The proportion of non-GYN samples has also been gradually increasing over time. This is probably because of an overall increase in cytologic exams (the subgroup proportions were not significantly different from the numbers in 2015).

The number of cytopathologic exams processed by commercial laboratories has been increasing. The average number of cytologic exams reported by the institutions showed a bipolar distribution; they significantly increased in university hospitals $(19,320$ in 2015 to 20,429 in 2018) and commercial laboratories $(158,814$ in 2015 to 173,393 in 2018) but decreased in general hospitals (11,080 in 2015 to 8,724 in 2018). This finding suggests that university hospitals and commercial laboratories have a need for more manpower.

LBP coverage has generally increased in all samples, especially thyroid FNA and urine samples based on the wide acceptance of the technology in these samples [9]. However, it decreased in the GYN and body fluid samples processed by the commercial laboratories. This seems to be primarily due to the increase in National Cancer Screening Program samples where LBP methods are not covered by insurance. Because the total number of cytologic exams is significantly increasing and cytopathology manpower is limited, expanding LBP coverage in the cancer screening program would be an effective strategy to manage increasing labor demands.
Over the past few years, the total number of GYN exams has been increasing and the number of cancer cases has been decreasing. At the same time, the ASC/SIL ratio, an important QC parameter for GYN cytology exams [10], has been increasing (the ASC rate has been increasing while the SIL rate has been decreasing). This finding seems to be due to the expansion of the recipient age group of the National Cancer Screening Program. Since 2016, the National Cancer Screening Program has covered women over the age of 20 (previously, only women over the age of 30 were covered), and the number of negative or ASC cases has increased while the number of SIL or cancer cases proportionally decreased [8]. The ASC/SIL ratio was more significantly increased in commercial laboratories than in the other institutions (3.68 in 2012 to 5.65 in 2018), which explains the impact of the changes in the National Cancer Screening Program samples. Interestingly, in correlation analyses, the institutions with more samples tended to have less LBP coverage and to report higher ASC/SIL ratios, and high LBP coverage tended to significantly correlate with lower ASC/SIL ratios. As the registered cytotechnologists that perform cytology screening were estimated as 386 in 2017, the average number of GYN samples screened by a cytotechnologist is 19,796.1 cases per year, approximately 79.2 cases per working day, which indicates that cytology laboratories in Korea have a labor-intensive working environment.

The major discordance (category $\mathrm{C}$ ) rate in the $\mathrm{CHCR}$ of the GYN samples has been significantly decreasing over time to a level as low as $0.52 \%$, and the unsatisfactory rate of GYN samples has been well controlled over time ( $0.14 \%$ in 2018). These findings show that the Continuous Quality Improvement program of KSC has gradually contributed to the improvement of cytopathologic exam quality in cytopathology laboratories in Korea over time.

In the PT, the average diagnosis concordance rate was approximately $85 \%$, and the major discordance (category C) rate was less than $1 \%(0.95 \%)$. The concordance rate was the highest in thyroid FNA (95.7\%), followed by body fluids (91.0\%), urine (85.2\%), and other FNA (83.6\%); it was the lowest in GYN cytology (75.2\%). This finding seems to be due to the sample characteristics and the varying degrees of complexity of the diagnostic categories. In GYN cytology, the major discordance (category $\mathrm{C}$ ) was less than $0.5 \%$, while the minimal and minor discordance (categories A and B) composed almost one-fourth of the total samples (24.3\%). This finding indirectly shows the complexity of the diagnostic category (Bethesda system [6]) of GYN cytology. In contrast, in thyroid FNA, the concordance rate was over $95 \%$. This seems to stem from the monotonous composition of PT samples. The occurrence of the minor categories of 
thyroid FNA, such as medullary carcinoma, poorly differentiated, or undifferentiated carcinoma was relatively rare, and these categories were not properly included in the PT sample pools. A more balanced sample composition for the PT should be carefully designed in the future. In comparison with the prior results of PT in 2004 and 2007, the concordant rate slightly but gradually increased from $73.0 \%$ in 2004 and $74.5 \%$ in 2007 to $75.2 \%$ in 2018 [1]. The major discordant rate (category C) also gradually decreased from $2.8 \%$ in 2004 and $2.0 \%$ in 2007 to $0.5 \%$ in 2018 [1]. However, because the discordance assessment criteria for PT have been slightly modified by the CQIKSC during the period as clinical treatment guidelines have changed, it is recommended that this data should be interpreted with care.

For the fourth part of the program, each participating institution has submitted candidate slide samples for the next PT program (182 institutions, 961 slides). However, there are several drawbacks to using these glass slides in the PT program. Not enough samples have been submitted every year. There is a possibility of sample loss or damage during packaging, handling, and storage, which can lead to the leakage of personal information. The level of diagnostic difficulty of each PT sample is variable, and the PT samples may be distributed disproportionately. The PT samples can easily become discolored over time during storage. Because of the aforementioned reasons, the introduction of a digital pathology system in the QC programs is being utilized in other programs such as United Kingdom National External Quality Assessment Site (UKNEQAS) and The Royal College of Pathologists of Australasia Quality Assurance Programs (RCPAQAP) [11,12]. In 2019, CQIKSC will also attempt to adopt the digital pathology system for the Continuous Quality Improvement programs with the collaboration of the Committee of Quality Assurance of the Korean Society of Pathologists. The efficacy of the digital pathology system in the Continuous Quality Improvement program will be assessed during its establishment.

With the results of this study, we confirmed that the Continuous Quality Improvement programs using the annual survey and the internal (CHCR) and external QC tests (PT) in the KSC have contributed to improved cytopathology practice performance quality by enhancing diagnostic accuracy. However, the high ASC/SIL ratio in a few institutions should be further monitored as the National Cancer Screening Programs expand over time. Active intervention and QC surveillance of each institution must be continued.

\section{Supplementary Information}

The Data Supplement is available with this article at https://doi.org/10.4132/ jptm.2020.02.26.

\section{Ethics Statement}

This study was reviewed and approved by the Institutional Review Board of The Catholic University of Korea, Yeouido St. Mary's Hospital (SC19ZCDI0091) with a waiver of consent.

\section{ORCID}

Yosep Chong https://orcid.org/0000-0001-8615-3064 Haeyoen Jung https://orcid.org/0000-0001-6950-5144 Jung-Soo Pyo https://orcid.org/0000-0003-0320-8088 Soon Won Hong https://orcid.org/0000-0002-0324-2414 Hoon Kyu Oh https://orcid.org/0000-0001-8793-1948

\section{Author Contributions}

Conceptualization: YC, SWH, HKO. Data curation: YC, HKO. Investigation: YC, HKO. Methodology: YC, HKO. Project administration: YC, HJ, JSP, HKO. Resources: YC, HJ, JSP, HKO. Supervision: SWH, HKO. Validation: YC, HKO. Visualization: YC, HJ, JSP. Writing-original draft: YC, HJ, JSP. Writing—review \& editing: YC, HJ, JSP, SWH, HKO.

\section{Conflicts of Interest}

Y.C., contributing editor and S.W.H., the senior editor of the Journal of Pathology and Translational Medicine, were not involved in the editorial evaluation or decision to publish this article. All remaining authors have declared no conflicts of interest

\section{Funding Statement}

No funding to declare.

\section{Acknowledgments}

We would like to thank Young Dong Seo for reviewing the manuscript and Eun-Mee Jeon for assisting with the data curation.

\section{References}

1. Lee HK, Kim SN, Khang SK, Kang CS, Yoon HK. Quality control program and its results of Korean Society for Cytopathologists. Korean J Cytopathol 2008; 19: 65-71.

2. Kim Y, Jun JK, Choi KS, Lee HY, Park EC. Overview of the National Cancer screening programme and the cancer screening status in Korea. Asian Pac J Cancer Prev 2011; 12: 725-30.

3. Suh M, Song S, Cho HN, et al. Trends in participation rates for the national cancer screening program in Korea, 2002-2012. Cancer Res Treat 2017; 49: 798-806.

4. Oh EJ, Jung CK, Kim DH, et al. Current Cytology Practices in Korea: A nationwide survey by the Korean Society for Cytopathology. J Pathol Transl Med 2017; 51: 579-87.

5. Jung M. National Cancer Screening Programs and evidence-based healthcare policy in South Korea. Health Policy 2015; 119: 26-32.

6. Nayar R, Wilbur DC. The Bethesda system for reporting cervical cytology: definitions, criteria, and explanatory notes. 3rd ed. Cham: Springer, 2015.

7. Cibas ES, Ali SZ. The 2017 Bethesda System for Reporting Thyroid Cytopathology. Thyroid 2017; 27: 1341-6.

8. Lim SC, Yoo CW. Current status of and perspectives on cervical cancer screening in Korea. J Pathol Transl Med 2019; 53: 210-6.

9. Chong Y, Ji SJ, Kang CS, Lee EJ. Can liquid-based preparation substitute for conventional smear in thyroid fine-needle aspiration? A 
systematic review based on meta-analysis. Endocr Connect 2017; 6: 817-29.

10. Nascimento AF, Cibas ES. The ASC/SIL ratio for cytopathologists as a quality control measure: a follow-up study. Am J Clin Pathol 2007; 128: 653-6.

11. Hodgson C, Cross P. Introduction and development of a digital diag- nostic non gynaecological diagnostic cytology interpretative scheme. Cytopathology 2018; 29(Suppl 1): 79.

12. Greaves J, Holzhauser D. Virtual cytopathology in an Austrailian EQA setting. In: 20th International Congress of Cytology; 2019 May 5-10; Sydney, Australia. 


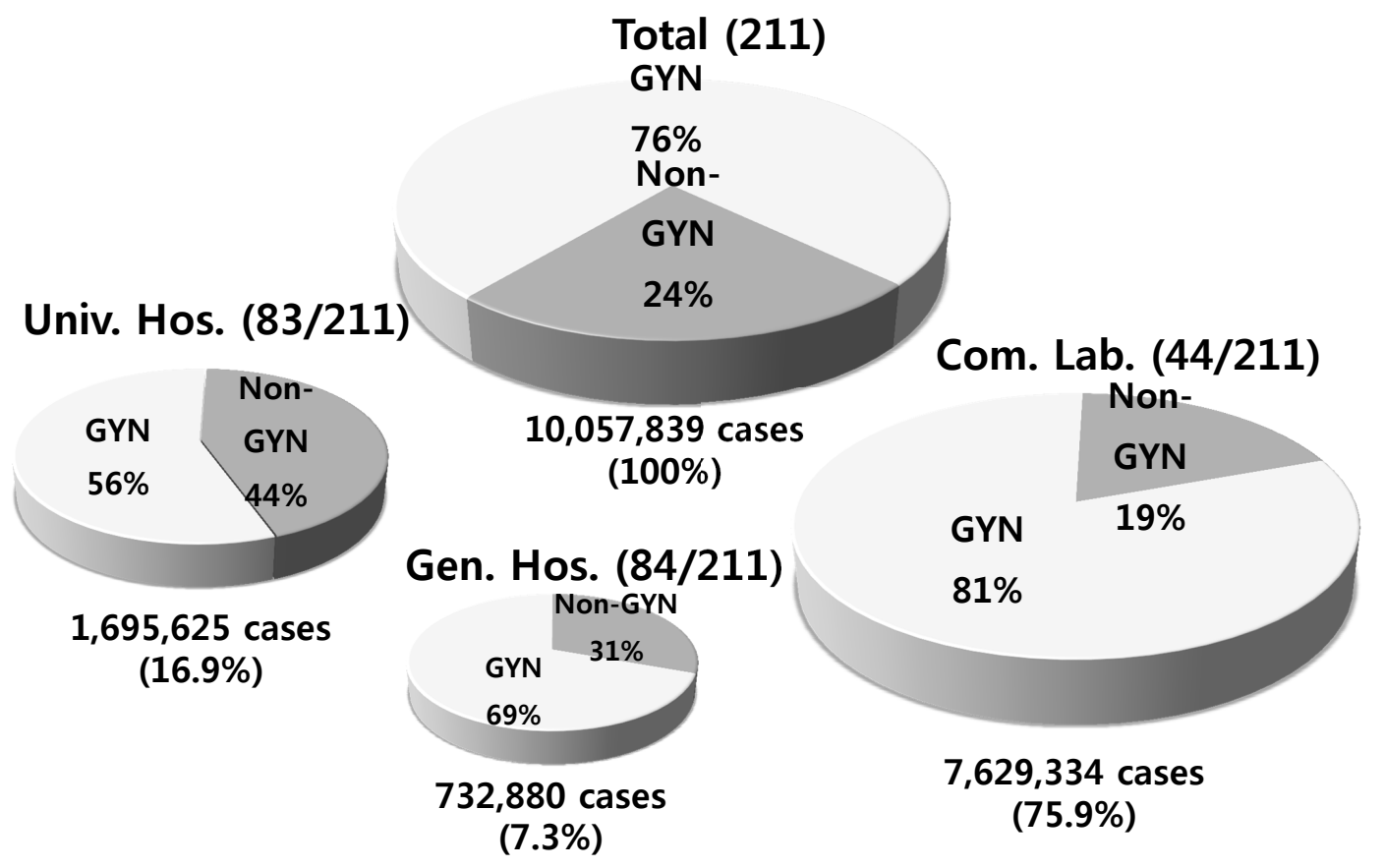

Supplementary Fig. S1. Number of cytopathologic exams according to institutions. GYN, gynecologic sample; Com. Lab., commercial laboratories; Gen. Hos., general hospitals; Univ. Hos., university hospitals. 